\title{
Coordenação das atividades produtivas na indústria brasileira de jogos eletrônicos: hierarquia, mercado ou aliança?
}

\author{
Alexandre Peruciaa,**, Alsones Balestrin ${ }^{\mathrm{b}}$, Jorge Verschoore ${ }^{\mathrm{c}}$ \\ a,*aperucia@unisinos.br, UNISINOS, Brasil \\ babalestrin@unisinos.br, UNISINOS, Brasil \\ cjorgevf@unisinos.br, UNISINOS, Brasil
}

\begin{abstract}
Resumo
Este estudo busca compreender como as empresas que desenvolvem jogos eletrônicos coordenam suas atividades de produção na indústria brasileira de jogos eletrônicos. Têm-se como base teórica os custos de transação e as relações interorganizacionais para a análise das estratégias de produção interna (hierarquia), contratação no mercado (mercado) e colaboração (aliança). A pesquisa foi conduzida junto às empresas da Associação Brasileira de Desenvolvedoras de Games (ABRAGAMES), e os dados foram coletados por meio de questionários eletrônicos e entrevistas em profundidade. Os resultados indicam a predominância da internalização das atividades de produção dos jogos, em função da existência de custos transacionais associados à necessidade de ativos específicos como especialização do conhecimento e escassez da mão de obra. Entretanto, observaram-se casos de estratégias de subcontratação alinhadas a atividades menos estratégicas para as empresas e de projetos colaborativos que potencializaram ganhos como redução de incerteza, flexibilidade organizacional, melhoria de processos e aprendizagem.
\end{abstract}

Palavras-chave

Custos de transação. Indústrias criativas. Jogos eletrônicos. Relações interorganizacionais.

\section{Introdução}

A indústria de jogos eletrônicos vem crescendo em importância econômica no cenário mundial. Segundo a DFC Intelligence, as vendas do mercado de jogos atingiram US\$ 33 bilhões no mundo em 2006, e a expectativa é de que esse número chegue a US\$ 47 bilhões até 2009 (DFC, 2007). Entretanto, mesmo com tal dimensão econômica, o mercado de jogos no Brasil é jovem e caracterizado por problemas estruturais, tais como: baixa renda da população, exclusão digital e pirataria. Assim, o país desempenha um papel modesto com um mercado estimado em R\$ 87,5 milhões (ASSOCIAÇÃO BRASILEIRA DAS DESENVOLVEDORAS DE GAMES, 2008). Apesar de embrionário, o mercado doméstico de jogos engloba uma nascente indústria criativa, cujo potencial mundial de crescimento é estimado em $72 \%$ entre 2005 e 2010, superando para o mesmo período os indicadores de setores criativos tradicionais como indústria fonográfica (29\%), cinema (29\%), esportes (40\%) e livros (16\%) (BARROWCLOUGH; KOZUL-WRIGHT, 2008). Tal apelo vem encorajando iniciativas locais, incluindo aquelas por parte do governo brasileiro, com programas de fomento à pesquisa, desenvolvimento tecnológico, geração de novos produtos e formação de mão de obra qualificada para empreendimentos de base tecnológica e inovadora (BRASIL, 2005).

Ao longo do seu desenvolvimento, a indústria de jogos eletrônicos evoluiu de um grupo de entusiastas criativos sem pretensões monetárias para um mercado complexo, representado por empresas interconectadas em uma cadeia de valor mundial (GRANTHAN; KAPLINSKY, 2005). Entre as atividades mais relevantes dessa cadeia, pode-se citar design, criação, desenvolvimento, teste e controle de qualidade (Quality Assurance - QA), edição/ publicação, distribuição e vendas (ASSOCIAÇÃO BRASILEIRA DAS DESENVOLVEDORAS DE GAMES, 2004; TSCHANG, 2005; BRASIL, 2005). 
É importante ressaltar que neste trabalho a indústria de jogos é definida como as empresas responsáveis pelas atividades de produção dos jogos, cujas etapas são: design, criação, desenvolvimento, teste e controle de qualidade (QA). 0 processo de design compreende a definição dos elementos basilares de um jogo, tais como a mecânica e princípios de interação com o jogador. A etapa de criação artística envolve a produção de áudio e os aspectos visuais do jogo, como o desenho e modelagem gráfica de personagens, cenários e animações. 0 desenvolvimento tecnológico representa essencialmente a programação do software do jogo. Na etapa de QA são identificadas possiveis falhas de software ou necessidades de acabamento para o produto. Segundo Tschang (2005), o processo de produção de um jogo tende a ser pouco sequencial e carrega um alto nível de incerteza até momentos antes da finalização do projeto, quando o produto pode ser experimentado em sua plenitude.

A facilidade de comunicação introduzida pela internet fez com que as empresas da indústria de jogos eletrônicos se beneficiassem do acesso global às informações, tecnologias e recursos de outras organizações, provocando a especialização da cadeia de valor. Assim, as organizações passaram a se voltar às suas competências centrais, intensificando suas transações com parceiros externos e potencializando novas formas de articulação da produção (BRASIL, 2005). A partir dessa realidade, torna-se relevante para a competitividade das empresas uma adequada estratégia de coordenação das suas atividades produtivas, tendo em vista as oportunidades de uma empresa produzir internamente ou interagir com outras organizações para o desenvolvimento de seus projetos.

Diante desse cenário, este trabalho toma por base as teorizações de autores como Coase (1937), Williamson (1975), Jarillo (1988) e Child, Faulkner, Tallman (2005), que subsidiam a compreensão acerca da decisão estratégica de coordenação das atividades produtivas, através da compra, produção interna ou cooperação. A partir das evidências quanto à internacionalização da indústria e a consequente especialização de sua cadeia de valor, este estudo busca responder à seguinte questão: como as empresas da indústria brasileira de jogos eletrônicos coordenam suas atividades de produção para atuarem no mercado?

Visando atingir esse objetivo, o artigo estrutura-se da seguinte forma: inicia no referencial teórico a discussão dos custos de transação como influentes na escolha da forma de coordenação das atividades econômicas e a emergência de um novo modo de coordenação: a estratégia colaborativa. $\mathrm{Na}$ sequência, apresenta um esquema conceitual de análise das decisões estratégicas de coordenação das atividades produtivas, uma sintese da metodologia utilizada na pesquisa, bem como a análise dos principais resultados. Ao final, destacam-se as principais conclusões e implicações da pesquisa.

\section{Referencial teórico}

\subsection{Economia dos custos de transação: produzir ou comprar?}

A empresa deverá produzir internamente ou contratar no mercado? Essa é uma questão central considerada por muitos estudos no campo da estratégica e de práticas de gestão. Influenciados pelos pioneiros trabalhos de Commons (1924, 1931) e Coase (1937), um significativo número de pesquisadores tem dedicado atenção ao estudo dessas duas formas de coordenação das atividades econômicas.

Destaca-se, nesse caso, Williamson (1975) que, seguramente, dedicou ao tema boa parte de suas pesquisas. 0 autor considera que 0 modo mais eficiente para a produção de um determinado bem seria a produção de cada um dos seus componentes por empresas especializadas. Os níveis de especialização das empresas fornecedoras levariam a curvas decrescentes de custos de produção, o que tornaria mais vantajoso para a empresa compradora adquirir tais componentes no mercado, a custos menores, do que produzi-los internamente. Assim, se é mais barato adquirir os componentes de uma empresa específica do que produzir internamente, então a opção mais adequada seria a compra no mercado. No entanto, o que se observa no contexto de negócios é que o comportamento das organizações, geralmente, não ocorre dessa forma.

A explicação para tal fato, segundo Williamson (1975), é que nas relações econômicas entre empresas existem os chamados "custos de transação" (CT). Esses custos são originados pelas inerentes dificuldades de negócios no mercado. As empresas incorrem em custos de transação toda vez que precisam definir, gerenciar e controlar suas transações com outras empresas, envolvendo custos, muitas vezes negligenciados, como os de negociação e de formalização de contratos, os de obtenção e de manutenção de clientes e os de acompanhamento de valores a receber. Alguns fatores influenciam decisivamente a intensidade dos custos de transação, são eles: "racionalidade limitada" do tomador de decisões, incerteza sobre o futuro e possibilidade de um "comportamento oportunista" por parte 
de determinados atores econômicos e os altos investimentos em ativos específicos (GEYSKENS; STEENKAMP; KUMAR, 2006). Logo, a falta de confiança nas relações da empresa com o seu ambiente e a possibilidade de comportamento oportunista por parte de alguns agentes representam questões centrais na existência de CT.

Por muito tempo essa dualidade entre "comprar" ou "produzir" esteve subjacente às decisões estratégicas da empresa. Na maioria das vezes, uma empresa tomaria a decisão racional de internalizar a produção de um determinado bem quando o custo de produção externa (CPE), ou seja, produção a partir de um fornecedor, mais o custo de transação (CT) associado a esse fornecimento, fosse maior do que o custo de produção interna (CPI) desse bem $(\mathrm{CPE}+\mathrm{CT}>\mathrm{CPI})$. Já a empresa adotaria a estratégia de contratação no mercado quando o $\mathrm{CPE}$, mais o CT, fosse menor que o CPI desse bem $(\mathrm{CPE}+\mathrm{CT}<\mathrm{CPI})$. Em síntese, há dois extremos possiveis de opções estratégicas para a empresa: de um lado a escolha pela produção interna dentro das próprias fronteiras hierárquicas da empresa e de outro a escolha pela aquisição no mercado dos componentes necessários.

Não obstante, Jarillo (1988) amplia a discussão quanto às estratégias de coordenação das atividades destacando que os CT podem ser afetados pela utilização de estratégias de cooperação entre as empresas. Nessa análise, o autor destaca o aspecto social da relação interorganizacional, sendo elementos como confiança e reciprocidade os indutores da ação cooperada, reduzindo o oportunismo entre os agentes econômicos que, segundo Williamson (1975), é apontado como um dos principais fatores na geração de CT. A estratégia de cooperação promove uma "atmosfera" de relacionamentos duradouros na qual a informação e o know how são trocados mais livremente entre as partes e os problemas são resolvidos de maneira eficiente. Além disso, adotando-se estratégias baseadas em cooperação, as empresas integrantes têm maior capacidade de adaptar-se às mudanças, reduzindo os custos de transação de incerteza ambiental. Conforme Jarillo (1993), esse diferencial é particularmente importante em mercados dinâmicos, com acelerado ritmo de evolução de inovações, curtos ciclos de vida dos produtos e pressões para se responder rapidamente às mudanças nas preferências dos clientes.

Diante dessas evidências, pode-se considerar que os arranjos cooperativos, pouco enfatizados pela perspectiva dos CT, tornam-se uma terceira forma de coordenação das atividades econômicas, entre a hierarquia (produzir) e o mercado (comprar).
A estratégia de cooperação aponta que entre produzir internamente ou adquirir os componentes de terceiros, existe a possibilidade de produção de um produto a partir de um conjunto de empresas. Essa estratégia poderá proporcionar à empresa os benefícios da hierarquia (melhor coordenação, redução dos custos de transação) com os benefícios da contratação (aumento de flexibilidade e ganhos de especialização na produção). A dimensão das estratégias colaborativas com redução dos custos de transação será analisada a seguir.

\subsection{Cooperar: a terceira via de coordenação das atividades produtivas}

Em seu estudo sobre ambientes organizacionais e políticas de negócios, Astley (1984) identificou três concepções particulares da natureza organizacional. A primeira é a visão do "cavaleiro solitário", na qual as empresas assumiam o papel de pioneiras, lutando contra as contingências ambientais, sendo forçadas a se adaptar às condições impostas. A segunda concepção é a da orientação egocêntrica, em que a escolha estratégica é determinada pela autossuficiência e pela tomada de ações independentes. A terceira concepção é herdada da orientação militar da estratégia, na qual as organizações são vistas como inimigas em um ambiente voraz, sendo motivadas a assumir posições estratégicas de enfrentamento no seu campo de batalha.

Em contraposição a essas concepções, Astley (1984) apresenta a ideia de colaboração como uma alternativa de política de negócios. Transformando os conceitos de competição para cooperação, de única organização para grupo de organizações e de separação para união, o conceito de estratégia colaborativa é definido como a conjunta formulação de políticas e implementação de ações pelos membros de coletividades interorganizacionais (BALESTRIN; VERSCHOORE, 2008). As estratégias coletivas representam a necessidade das organizações de promover ações de cooperação para lidar com suas naturais interdependências dinâmicas, da mesma forma que, na natureza, muitos animais aglutinam-se em grupos para se proteger e sobreviver.

Como decorrência, a ideia de estratégias coletivas assumiu um relevante papel nas decisões empresariais pelas vantagens que apresenta. Os autores Ebers e Jarillo (1998), por exemplo, destacam que, com a adoção de estratégias coletivas, uma empresa consegue alcançar e sustentar diferenciais competitivos a partir das seguintes vantagens: 
a) aprendizado mútuo, que levará a empresa a suportar melhor o processo de desenvolvimento de novos produtos;

b) coespecialidade, em que as empresas participantes tornam-se lucrativas em novos nichos de produtos e mercados;

c) melhor fluxo de informação, facilitando a coordenação do fluxo de recursos entre as empresas e reduzindo a incerteza nas relações; e

d) economias de escala, resultado de investimentos conjuntos, como, por exemplo, em novos projetos de desenvolvimento de produtos.

No desenrolar da década de 90, o conceito de estratégia coletiva agregou a ideia de coopetição. Dois autores americanos, Nalebuff e Brandenburger (1989), trouxeram à tona a discussão de que as empresas deveriam pesar as consequências de suas estratégias competitivas e colaborativas. Ao adotarem um comportamento individualista e exclusivamente competitivo, as companhias poderiam sofrer perdas irreparáveis, tal como ocorre, usualmente, nas guerras de preços. Por outro lado, a visão colaborativa abre espaço para ações oportunistas de competidores ardilosos, como o roubo de segredos, por exemplo. Como solução, as empresas devem conhecer os prós e contras das estratégias individuais e colaborativas e tomar suas decisões levando em consideração o ambiente concorrencial no qual se insere e as empresas com as quais estabelece relacionamentos de negócio.

Visando ampliar as discussões e auxiliar o gestor na definição de uma estratégia que melhor componha a utilização desses três modelos comprar, produzir, cooperar -, Child, Faulkner, Tallman (2005) apresentam a Matriz CPC (comprar, produzir ou cooperar). A Matriz CPC (Figura 1) visa a compreensão da maneira mais adequada de conduzir as atividades produtivas da empresa e tomar as decisões de produção interna, compra no mercado ou cooperação com um parceiro. Para tanto, ela combina nos seus dois eixos a importância estratégica de uma determinada atividade e a competência da empresa em relação às melhores do mercado para realizar tal atividade.

A lógica da Matriz CPC centra-se no fato de que mesmo as maiores empresas não podem mais executar todas as atividades produtivasinternamente, necessitando optar por quais atividades deve realizar. Como se pode notar na Figura 1, a empresa possui três diferentes possibilidades de decisão em relação a uma determinada atividade produtiva: ou ela produz internamente, ou a adquire no mercado, ou se alia com outras empresas para executá-la colaborativamente. As duas primeiras escolhas representam estratégias de competição individual da firma, enquanto a última representa a opção de cooperar com um parceiro.

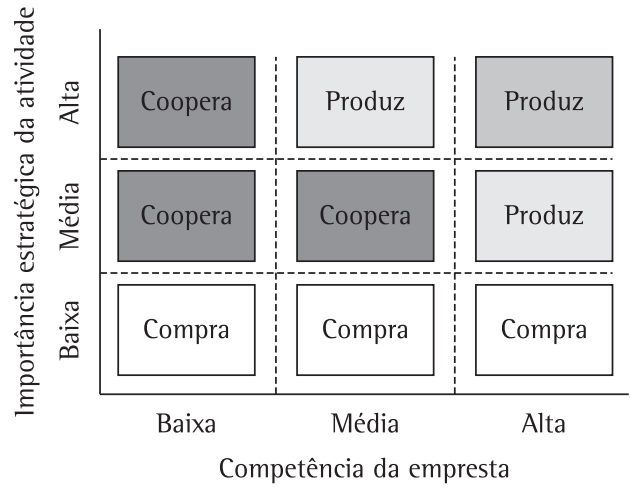

Figura 1. Matriz CPC. Fonte: adaptada de Child, Faulkner e Tallman (2005).

Seguindo a orientação da Matriz CPC, se uma determinada atividade tem baixa importância estratégica para os negócios da empresa, a opção mais adequada, independentemente da competência da empresa para realizá-la, é adquirir do melhor fornecedor do mercado. Essas são atividades, como, por exemplo, limpeza, segurança e alimentação dos funcionários, para as quais existem diversos prestadores de serviços especializados. Por outro lado, se determinada atividade tem média ou alta importância estratégica para a empresa, as decisões tornam-se mais complexas. Caso a empresa tenha uma competência entre média e alta na execução da atividade, a melhor opção será realizá-la, utilizando-se das competências internas e transformando-as em um dos seus diferenciais competitivos.

Contudo, como se percebe que as empresas não possuem todas as competências para a execução de grande parte das atividades com média e alta importância estratégica, a melhor opção nesses casos é recorrer à colaboração com parceiros para desenvolvê-las, geralmente com maior eficiência, menor custo e prazo.

\section{Método de pesquisa}

0 método utilizado compreende um estudo de caso da indústria brasileira de jogos eletrônicos, com foco nas empresas que produzem jogos. Essa indústria é formada por aproximadamente 60 empresas (ASSOCIAÇÃO BRASILEIRA DAS DESENVOLVEDORAS DE GAMES, 2004). Para levantamento dos dados junto às empresas da indústria brasileira foram realizadas duas etapas complementares de coleta: questionário eletrônico e entrevistas em profundidade (Quadro 1).

a) Questionário eletrônico - Para essa etapa, foram analisadas as empresas que produzem jogos eletrônicos associadas à Associação Brasileira dos 
Quadro 1. Variáveis analisadas e fontes de evidências.

\begin{tabular}{|c|c|c|}
\hline Conceitos norteadores da pesquisa & Variáveis de análise & Fontes de evidência \\
\hline $\begin{array}{c}\text { Características da indústria brasileira } \\
\text { de jogos eletrônicos }\end{array}$ & $\begin{array}{c}\text { Perfil das empresas e da indústria; atividades } \\
\text { da cadeia de valor desenvolvidas }\end{array}$ & Questionário eletrônico \\
\hline Importância estratégica das atividades & $\begin{array}{c}\text { Nível de importância estratégica na } \\
\text { produção de jogos eletrônicos }\end{array}$ & $\begin{array}{c}\text { Questionário eletrônico; } \\
\text { entrevista }\end{array}$ \\
\hline Nível de competência das empresas & $\begin{array}{c}\text { Nível de competência da empresa para realização } \\
\text { das atividades de produção de jogos eletrônicos }\end{array}$ & $\begin{array}{c}\text { Questionário eletrônico; } \\
\text { entrevista }\end{array}$ \\
\hline Estratégia de coordenação utilizada & $\begin{array}{c}\text { Produção interna; compra no mercado; } \\
\text { cooperação com empresas parceiras }\end{array}$ & $\begin{array}{c}\text { Questionário eletrônico; } \\
\text { entrevista }\end{array}$ \\
\hline
\end{tabular}

Fonte: elaborado pelos autores.

Desenvolvedores de Games (ABRAGAMES). Os dados foram coletados a partir de um questionário eletrônico na internet, abrangendo questões abertas e fechadas, dividas em três subgrupos:

i) questões de identificação das empresas e dos entrevistados;

ii) questões sobre as atividades da cadeia de valor contempladas pelas empresas (design, criação, desenvolvimento, testes e controle de qualidade, edição digital / publicação, distribuição e vendas) e os níveis de produção interna e compra no mercado para cada atividade;

iii)importância estratégica das atividades para a empresa, e nível de competência nessas atividades. 0 questionário foi validado junto a especialistas, em reunião realizada em julho de 2007 e disponibilizado para as empresas da ABRAGAMES entre agosto e setembro de 2007. Obteve-se retorno de 22 das 26 empresas associadas (taxa de resposta de 84,6\%);

b) Entrevista em profundidade - Com as empresas mapeadas pela primeira etapa, realizou-se a seleção daquelas que fariam parte das entrevistas. Os critérios adotados foram respectivamente:

i) atuar com produção de jogos;

ii) dez ou mais empregados (priorizando vínculos formais);

iii) atendimento às principais plataformas de jogos (celular, on-line, PC, console);

iv) experiência com alianças e internacionalização. Esses critérios foram adotados para a seleção de empresas com maior experiência no mercado, em virtude da realidade embrionária da indústria local. Foram selecionadas nove empresas para as entrevistas, realizadas em cinco cidades (Campinas, Porto Alegre, Recife, São Leopoldo e São Paulo) entre outubro e dezembro de 2007. As entrevistas foram realizadas junto aos gestores das empresas, com uma hora e meia de duração, orientada por um questionário semiestruturado, e registradas com gravador.

A análise dos dados ocorreu a partir da transcrição das entrevistas e da análise de conteúdo. Assim, identificaram-se frequências de expressões, qualificadas de acordo com as unidades de análise do referencial teórico, permitindo interpretações a partir das evidências encontradas (HAIR et al., 2005). Enquanto os dados quantitativos permitiram mapear as empresas da indústria e descrever suas características, as entrevistas em profundidade auxiliaram na compreensão das estratégias de coordenação adotadas pelas organizações. Por questões de confidencialidade, as empresas entrevistadas serão referidas pelas iniciais E1 a E9.

\section{Resultados e discussões}

\subsection{Características da indústria brasileira de jogos eletrônicos}

As 22 empresas do estudo caracterizam-se como micro ou pequenas empresas (de 2 a 62 empregados), com uma média de 17 empregados, predominando o profissional contratado com vínculo empregatício (42\% dos empregados). Das empresas que declararam receitas em 2005 e 2006 (59\% das respondentes), $89 \%$ registraram aumento no faturamento, perfazendo um crescimento anual médio de 56\%. Analisando-se as atividades da cadeia de valor (Tabela 1), observa-se que a configuração mais comum é a da empresa que exerce atividades de design, criação e desenvolvimento de jogos.

Entre as empresas pesquisadas, $68,2 \%$ atuam no mercado internacional. As razões mais comuns são:

i) maior demanda por serviços no exterior;

ii) desenvolvimento de produtos mais sofisticados;

iii) atenuação do impacto da pirataria e do baixo poder de compra no Brasil;

iv) busca por visibilidade e projeção da empresa; e

v) vantagem da mão de obra mais barata no Brasil. Dentre os maiores mercados internacionais destacam-se os Estados Unidos, com destino de $73,3 \%$ das exportações. Mesmo que a maioria das empresas atue no mercado internacional, as vendas no exterior são responsáveis, em média, por apenas 39\% das receitas totais das empresas. 
Tabela 1. Atividades realizadas pelas empresas.

\begin{tabular}{ccc}
\hline Atividade & $\begin{array}{c}\text { Percentual de } \\
\text { empresas que realizam } \\
\text { a atividade (\%) }\end{array}$ & $\begin{array}{c}\text { Número de } \\
\text { empresas }\end{array}$ \\
\hline Design & 68,2 & 15 \\
Criação & 81,8 & 18 \\
Desenvolvimento & 95,5 & 21 \\
Teste e QA & 31,8 & 7 \\
Edição digital/ & 31,8 & 7 \\
Publicação & 13,6 & 3 \\
Distribuição & 13,6 & 3 \\
Vendas & &
\end{tabular}

Fonte: elaborado pelos autores.

Quanto às plataformas tecnológicas dos jogos, observa-se que o Personal Computer (PC) e a internet são as mais adotadas pelas empresas (63,6\% e 59,1\% dos respondentes respectivamente). Os dados também indicam que essas plataformas representam, para as empresas, suas maiores fontes de receita. Pode-se observar a orientação das empresas para a produção de jogos para as plataformas internet, celular e PC que representam segmentos com poucas barreiras de entrada e volume de vendas menores. Em paralelo, nota-se uma modesta representatividade da produção para plataforma console (videogame) que, conforme a Brasil (2005), representa 75\% do volume de vendas da indústria. Essa evidência pode ser explicada pelo fato de a produção de jogos para consoles ter acesso restringido pelos fabricantes (sem representação no Brasil), os quais exigem investimentos financeiros e padrões de qualidade além das possibilidades da maioria das empresas brasileiras.

\subsection{Nível de importância estratégica das atividades}

A importância estratégica está diretamente alinhada ao foco e posicionamento do negócio. Por exemplo, se o grande diferencial da organização está em sua tecnologia de programação de jogos, o desenvolvimento tende a ser uma atividade de alta importância estratégica. A Tabela 2 apresenta as respostas dos empresários com relação à importância estratégica de suas atividades.

A criação surge aqui como a atividade de mais alta importância estratégica (86,4\% das empresas), seguida pelo desenvolvimento (81,8\%) e design $(72,7 \%)$. Nota-se que, na definição deste estudo, criação envolve atividades de cunho artístico, como produção sonora e visual. Entretanto, nas entrevistas constatou-se que boa parte dos empresários entende essa etapa como também sendo design, onde é elaborado o conceito do jogo. Dessa forma, há a possibilidade de que o design tenha uma importância maior do que os resultados aparentam.

Uma análise mais detalhada revela que mais da metade das empresas $(54,5 \%)$ considera em conjunto as atividades de design, de criação e de desenvolvimento como as atividades altamente estratégicas. Identifica-se que a partir do elo de teste, seguindo em direção aos elos comerciais, a percepção de importância estratégica cai consistentemente. Esses indicadores reforçam uma possível orientação da maior parte das empresas para a produção interna do "jogo inteiro" e não para a especialização em etapas da produção de um jogo.

\subsection{Nível de competência interna para a realização das atividades}

0 nível de competência define a capacidade de a empresa realizar a atividade tão bem quanto as melhores empresas do mercado. A Tabela 3 apresenta as respostas dos empresários com relação ao nível de competência que julgam possuir para a realização de suas atividades produtivas.

Segundo as evidências, o desenvolvimento foi a atividade com o maior número de empresas que demonstram alta competência $(77,3 \%$ ou 17 empresas), seguida de design e criação, com $68,2 \%$ (15 empresas) cada. Assim a atividade de desenvolvimento se destaca como a melhor competência das empresas de jogos, evidência alinhada com o perfil da indústria descrito pela Brasil (2005) que caracteriza as empresas de jogos brasileiras como aquelas formadas por jovens profissionais de alta capacitação tecnológica.

Pela maior inclinação à produção, percebe-se que as empresas reportam menor competência na realização das atividades comerciais, entretanto mesmo na produção há uma diminuição forte do número de empresas com competência para a atividade de teste e QA. De forma geral, para as atividades produtivas realizadas pelas empresas, as competências são normalmente reportadas como altas ou no mínimo médias, o que combinado a importância estratégica das atividades (em geral altas) pode sugerir pouco espaço para coordenação de atividades através da compra ou cooperação.

\subsection{Estratégias de coordenação das atividades produtivas}

De modo geral, o que se percebe é que a grande maioria das empresas considera os elos produtivos (design, criação e desenvolvimento) como de alta importância estratégica. Da mesma forma, a maioria delas espera ter alta, ou no mínimo 
Tabela 2. Importância estratégica das atividades desenvolvidas pelas empresas.

\begin{tabular}{ccccccccc}
\hline & \multicolumn{7}{c}{ Importância estratégica } \\
Atividade & (Número de empresas respondentes/percentual de empresas para $\mathrm{n}=22$ ) \\
\cline { 2 - 9 } & Alta & $\%$ & Média & $\%$ & Baixa & $\%$ & Não informado & $\%$ \\
\hline Design & 16 & 72,70 & 3 & 13,60 & 1 & 4,50 & 2 & 9,20 \\
Criação & 19 & 86,40 & 1 & 4,50 & 1 & 4,50 & 1 & 4,60 \\
Desenvolvimento & 18 & 81,80 & 4 & 18,20 & 0 & 0,00 & 0 & 0,00 \\
Teste e QA & 12 & 54,50 & 6 & 27,30 & 2 & 9,10 & 2 & 9,10 \\
Publicação/Edição & 7 & 31,80 & 3 & 13,60 & 2 & 9,10 & 10 & 45,50 \\
Distribuição & 7 & 31,80 & 3 & 13,60 & 1 & 4,50 & 11 & 50,10 \\
Venda/Varejo & 8 & 36,40 & 1 & 4,50 & 2 & 9,10 & 11 & 50,00 \\
\hline
\end{tabular}

Fonte: elaborado pelos autores.

Tabela 3. Nível de competência nas atividades.

\begin{tabular}{ccccccccc}
\hline & \multicolumn{7}{c}{ Nível de competência } \\
Atividade & \multicolumn{7}{c}{ (Número de empresas*/percentual de empresas para $\mathbf{n}=22$ ) } \\
\cline { 2 - 9 } & Alta & $\%$ & Média & $\%$ & Baixa & $\%$ & Não informado & $\%$ \\
\hline Design & 15 & 68,20 & 4 & 18,20 & 1 & 4,50 & 2 & 9,10 \\
Criação & 15 & 68,20 & 6 & 27,30 & 0 & 0,00 & 1 & 4,50 \\
Desenvolvimento & 17 & 77,30 & 5 & 22,70 & 0 & 0,00 & 0 & 0,00 \\
Teste e QA & 7 & 31,80 & 6 & 27,30 & 4 & 18,20 & 5 & 22,70 \\
Publicação/Edição & 4 & 18,20 & 1 & 4,50 & 3 & 13,60 & 14 & 63,70 \\
Distribuição & 2 & 9,10 & 3 & 13,60 & 4 & 18,20 & 13 & 59,10 \\
Venda/Varejo & 2 & 9,10 & 0 & 0,00 & 5 & 22,70 & 15 & 68,20 \\
\hline
\end{tabular}

Fonte: elaborado pelos autores.

Tabela 4. Decisão estratégica com base na Matriz CPC.

\begin{tabular}{|c|c|c|c|c|c|c|}
\hline \multirow{2}{*}{ Atividade } & \multicolumn{2}{|c|}{ Comprar } & \multicolumn{2}{|c|}{ Produzir } & \multicolumn{2}{|c|}{ Cooperar } \\
\hline & Empresas* & $\%$ & Empresas* & $\%$ & Empresas* & $\%$ \\
\hline Design & 1 & 4,55 & 18 & 81,82 & 1 & 4,55 \\
\hline Criação & 1 & 4,55 & 20 & 90,91 & 0 & 0,00 \\
\hline Desenvolvimento & 0 & 0,00 & 20 & 90,91 & 2 & 9,09 \\
\hline Teste e QA & 2 & 9,09 & 10 & 45,45 & 5 & 22,73 \\
\hline Publicação/Edição & 0 & 0,00 & 4 & 18,18 & 4 & 18,18 \\
\hline Distribuição & 0 & 0,00 & 4 & 18,18 & 5 & 22,73 \\
\hline Venda/Varejo & 1 & 4,55 & 2 & 9,09 & 4 & 18,18 \\
\hline
\end{tabular}

${ }^{*}$ Consideram-se os respondentes que indicaram respostas válidas para importância estratégica e competência. 0s percentuais são para $n=22$. Fonte: elaborado pelos autores.

média competência nas mesmas atividades. Essa configuração traz implicações estratégicas, segundo Child, Faulkner, Tallman (2005), pois a tendência é a de haver uma inclinação forte para a internalização, diminuindo as possibilidades de especialização através de compra ou cooperação (Tabela 4).

A Matriz CPC (CHILD; FAULKNER; TALLMAN, 2005) reforça a ideia de que as empresas se orientam estrategicamente para a produção de um jogo inteiro (atividades de design, criação e desenvolvimento). Apenas em design e desenvolvimento se verifica a cooperação como estratégia indicada, ainda assim, para um número extremamente restrito de empresas.
As possibilidades de redução da verticalização tornam-se mais factíveis a partir do elo de teste e QA em direção aos elos comerciais. Como exemplos destacam-se o teste e o QA, e a distribuição, onde os indicadores de cinco empresas sugerem a utilização de estratégias colaborativas. Como nessas atividades as empresas apresentam menor competência interna, ao mesmo tempo em que considera como atividades relevantes, a orientação da Matriz CPC (CHILD; FAULKNER; TALLMAN, 2005) sugere a utilização, nesse caso, de projetos de cooperação com outras empresas. As decisões estratégicas face à importância estratégica e competência percebida pelos empresários são apresentadas no Quadro 2. 
Quadro 2. Estratégias adotadas na indústria.

\begin{tabular}{|c|c|c|c|}
\hline Empresa & Compra & Produz & Coopera \\
\hline E1 & $\begin{array}{c}\text { Criação (áudio), devido à pequena } \\
\text { demanda que não justifica } \\
\text { equipe interna. }\end{array}$ & $\begin{array}{c}\text { Design, criação (parte visual), por } \\
\text { questões de redução de custo; e } \\
\text { desenvolvimento, por ser estratégico. }\end{array}$ & Nenhuma atividade produtiva. \\
\hline E2 & $\begin{array}{c}\text { Criação, no que se refere } \\
\text { ao áudio. }\end{array}$ & $\begin{array}{l}\text { Desenvolvimento e teste e QA, por } \\
\text { questões de redução de custos e } \\
\text { diferenciação tecnológica. }\end{array}$ & $\begin{array}{l}\text { Design e criação, para reduzir } \\
\text { custo e diluir risco. Produção } \\
\text { conjunta de novos jogos para } \\
\text { mercado internacional através de } \\
\text { parceiros de roteirização e arte. }\end{array}$ \\
\hline E3 & $\begin{array}{l}\text { Criação, quando há excesso } \\
\text { de volume de trabalho. }\end{array}$ & $\begin{array}{c}\text { Design, criação, desenvolvimento } \\
\text { e teste e QA, pois há um núcleo } \\
\text { formado por sócios que contemplam } \\
\text { todas as atividades produtivas. }\end{array}$ & $\begin{array}{l}\text { Criação, através de rede de } \\
\text { produção artística. }\end{array}$ \\
\hline E4 & $\begin{array}{l}\text { Criação, quando se trata de } \\
\text { atividades de pouca demanda. }\end{array}$ & $\begin{array}{c}\text { Design, criação, desenvolvimento e } \\
\text { teste e QA, para garantir qualidade } \\
\text { e proteção do código-fonte do } \\
\text { software. } \\
\text { Publicação e venda, pois o portal de } \\
\text { jogos é o novo negócio da empresa. }\end{array}$ & $\begin{array}{l}\text { Distribuição, para expandir } \\
\text { visibilidade do canal } \\
\text { de jogos on-line. } \\
\text { Publicação, para trabalhar } \\
\text { em parceria com } \\
\text { desenvolvedoras de jogos e } \\
\text { criar conteúdo para o portal. }\end{array}$ \\
\hline E5 & $\begin{array}{l}\text { Design, criação, desenvolvimento e } \\
\text { teste e QA, quando há excesso de } \\
\text { demanda e o projeto não é estratégico. }\end{array}$ & $\begin{array}{l}\text { Design, criação, desenvolvimento, } \\
\text { teste e QA, pois se orienta à } \\
\text { produção do jogo inteiro. }\end{array}$ & $\begin{array}{c}\text { Desenvolvimento, para produção } \\
\text { de novos jogos para o } \\
\text { mercado internacional. }\end{array}$ \\
\hline E6 & $\begin{array}{l}\text { Criação (áudio), desenvolvimento } \\
\text { (porting) e teste e QA, quando for } \\
\text { mais rápido que produzir. }\end{array}$ & $\begin{array}{l}\text { Design, criação, desenvolvimento e } \\
\text { teste e QA, para reduzir custo. }\end{array}$ & Nenhuma atividade produtiva. \\
\hline E7 & $\begin{array}{c}\text { Design e criação, quando há } \\
\text { necessidade de especialistas como } \\
\text { pedagogos e redatores, ou em casos } \\
\text { de excesso de demanda. }\end{array}$ & $\begin{array}{l}\text { Design, criação, desenvolvimento, } \\
\text { teste e QA, pois há um núcleo-base } \\
\text { na empresa que contempla todas as } \\
\text { atividades produtivas. }\end{array}$ & $\begin{array}{l}\text { Design e Criação, através de } \\
\text { rede de especialistas e artistas. } \\
\text { Desenvolvimento, na criação } \\
\text { de novos jogos para } \\
\text { mercado internacional. }\end{array}$ \\
\hline E8 & $\begin{array}{l}\text { Design, criação, desenvolvimento, teste } \\
\text { e QA, quando o custo é menor e o } \\
\text { projeto não é estratégico. }\end{array}$ & $\begin{array}{c}\text { Design, criação, desenvolvimento, } \\
\text { teste e QA, pois são importantes } \\
\text { para a coesão do jogo, e quando os } \\
\text { projetos são estratégicos. }\end{array}$ & $\begin{array}{l}\text { Desenvolvimento, através da } \\
\text { qualificação de fornecedores. }\end{array}$ \\
\hline E9 & $\begin{array}{l}\text { Design, criação, desenvolvimento, } \\
\text { teste e QA, para redução de custo e } \\
\text { quando o projeto não é estratégico. } \\
\text { Publicação e distribuição, para } \\
\text { atingir mercados externos. }\end{array}$ & $\begin{array}{c}\text { Design, criação, desenvolvimento, } \\
\text { teste e QA, publicação e } \\
\text { distribuição, pois a empresa } \\
\text { se orienta para a produção e } \\
\text { publicação de jogos para celular. }\end{array}$ & Nenhuma atividade produtiva. \\
\hline
\end{tabular}

Fonte: elaborado pelos autores.

Observa-se um elevado nível de internalização das atividades de produção de um jogo por parte das empresas. Em alguns casos, pode-se perceber que os altos níveis de internalização são explicados pela falta de foco ou posicionamento estratégico das organizações, conforme se nota no argumento de um empresário, "[...] Acho que todas as atividades são essenciais, então somos especialistas em tudo" (E8, 2007).

Entretanto pode-se notar que a produção de um jogo está ligada a uma alta interdependência de atividades como designe programação de tecnologia (desenvolvimento), conforme destaca o empresário de E3, "[...] O design do jogo para ser feito fora teria que ser muito colaborativo, então nessa atividade as pessoas teriam que estar fisicamente presentes. A tendência é de ser (design) uma coisa viva no projeto". "[...] Ele vai evoluindo ao longo do projeto. E na programação, poderia se fazer fora em módulos, mas eu acho complicado porque exige um encaixe mais perfeito das coisas" (E3, 2007).

Essa alta interdependência pode exigir do processo de produção de um jogo uma série de atividades com elevados graus de ativos de conhecimentos específicos (GEYSKENS;STEENKAMP; KUMAR, 2006), requerendo investimentos que não são facilmente encontrados no momento de externalização das atividades, o que poderia incorrer em significativos custos de transação (WILLIAMSON, 1975).

Assim, a mão de obra tende a ser um ativo bastante específico e escasso na indústria brasileira, conforme destaca o então presidente da ABRAGAMES, André Penha, "[...] O Brasil, pelo fato de ser uma indústria muito jovem, tem poucas pessoas com 
larga experiência na área. Você consegue contar nos dedos quem no Brasil tem mais de cinco ou seis anos de experiência na indústria de jogos".

Essa evidência é reforçada pelo empresário de E3, "[...] Se fôssemos expandir a equipe de arte ou programação, teríamos dificuldades em conseguir profissionais com experiência aqui no Brasil. $E$ um mercado específico, e experiência prática é realmente algo muito valorizado, mas que quase ninguém tem" (E3, 2007).

Sendo vital a qualidade da mão de obra, sua escassez poderia contribuir para a verticalização na produção, buscando assim fugir dos elevados custos com a busca de outras empresas no mercado, o que justificaria, segundo Williamson (1975) e Geyskens, Steenkamp e Kumar (2006), uma estratégia de internalização, mesmo em pequenas empresas (JARILLO, 1993). Assim, as empresas acabam por desenvolver seus talentos internamente como uma forma de evitar custos de transação, em especial relacionados aos investimentos elevados em ativos de conhecimento e experiência referente à qualificação requerida para a produção dos jogos.

Além dos elevados custos em ativos específicos na produção de jogos, há algumas evidências relacionadas à incipiência da indústria nacional, que justificam essa orientação para internalização. As empresas em geral são pequenas e têm a participação ativa de sócios, com grande experiência nas atividades-chave de produção de jogos, devido ao alto nível de especialização requerido, conforme destaca o empresário de E8, "[...] Jogos se utilizam da mais alta tecnologia, por isso se utilizam dos profissionais mais caros de Tl e mais gabaritados no mercado. Podem até ser profissionais mais novos, mas são os mais capazes" (E8, 2007).

Essa questão fica evidente ao analisar pesquisas internacionais, demonstrando que a indústria de jogos surgiu nos mercados mais desenvolvidos por iniciativa de entusiastas criativos com alta capacitação técnica (GRANTHAM; KAPLINSKY, 2005). No primeiro momento as empresas da indústria internalizavam praticamente todas as atividades produtivas devido ao pequeno tamanho do mercado (JOHNS, 2006), sofrendo uma posterior desverticalização com a evolução dele, o aumento da competição e a consequente especialização dos atores (WILLIAMS, 2002; GRANTHAM; KAPLINSKY, 2005).

Ao comparar a evolução da indústria internacional, pode-se verificar que a indústria brasileira de jogos, ainda embrionária, poderá seguir um caminho de desverticalização, no momento em que aumente o número de empresas, a disponibilidade de mão de obra especializada e o fortalecimento do setor como um todo. Essa tendência pode ser percebida na observação do empresário de E5 ao retratar a diferença de estágio de desenvolvimento entre aos maiores mercados e o Brasil, "[...] A cada ano a gente tenta aumentar nosso foco; e isso é uma coisa que a gente enxergou inclusive no mercado internacional. A gente encontrou empresas de jogos que produziam apenas cenários de cidades para serem inseridos nos jogos de outras empresas, e isso é uma coisa bem específica. Nós fazemos no Brasil jogos para PC, console e jogos para propaganda que envolvem um outro know how e, além de games, você tem que trabalhar com a marca também" (E5, 2007).

A segunda observação que chama atenção, com relação às decisões estratégicas de coordenação, diz respeito à subcontratação no mercado. Nesse caso, há uma forte constância na compra de atividades de criação, tais como artes gráficas e música. Outro ponto de possível observação é que algumas empresas, em casos específicos apresentados a seguir, chegam a externalizar todas as atividades produtivas.

No que se refere à atividade de criação, que os empresários costumam chamar de arte, observa-se em alguns depoimentos que esta é uma atividade mais acessível de subcontratar. Segundo o empresário de E3, "[...] O mais simples de se contratar no mercado, em minha opinião, é arte (criação), que inclui o visual, som, música. No desenvolvimento de um jogo que tenha 100 personagens, a gente desenvolve 10 dos mais importantes e passa como referência para o outsourcing dos outros 90' (E3, 2007).

A criação parece exigir ativos menos específicos (WILLIAMSON, 1975; GEYSKENS; STEENKAMP; KUMAR, 2006) com maior oferta de profissionais no mercado e, possivelmente, com menores investimentos em ativos específicos, impactaria em menores custos de transação, como complementa o empresário de E3, "[...] Na arte (criação), visualmente tu observas o que foi entregue, tu consegues dizer na hora o que deve ser modificado, se funciona, se não funciona" (E3, 2007).

Os demais casos de subcontratação, que não se restringem apenas à criação, levam em consideração basicamente três condições: a demanda, o custo e se a atividade é estratégica para a empresa. Se as atividades tendem a representar demandas muito pontuais, que não justificam a manutenção de equipe interna, a tendência é subcontratar do melhor fornecedor do mercado, conforme orientação de Child, Faulkner, Tallman (2005) e evidenciado na percepção do empresário de E4, “[...] Ás vezes a parte de ilustração, uma coisa mais específica, de interface, que não tem volume de trabalho, não faz sentido a gente manter profissionais ociosos, a gente acaba indo no mercado para contratar" (E4, 2007). 
Além de demandas pontuais, a subcontratação também ocorre nos casos onde há excesso de demanda. Nessas situações começam a pesar questões de custos, mas também a própria relevância estratégica do projeto. Como apontado por Child, Faulkner, Tallman (2005), quando os projetos tendem a ter menor importância estratégica eles tendem a ser subcontratados. Questões de custos e relevância estratégica, frente a grandes demandas, podem ser observadas em comentários como o do empresário de E5, “[...] Terceirizamos quando temos a capacidade da empresa já completa, e quando éuma atividade que não é estrategicamente interessante". "[...] Tem o critério financeiro também, se quem faz essa atividade faz mais barato e melhor, ou seja, custo-benefício" (E5, 2007).

Em geral as decisões estratégicas de coordenação giram em torno da produção interna, seguida da subcontratação no mercado de demandas pontuais ou excedentes de menor sofisticação, de menor importância estratégica para a empresa e de menor valor financeiro. Embora incipiente na indústria brasileira de jogos eletrônicos, foi possível identificar alguns casos da terceira forma de coordenação: a estratégias de cooperação. As estratégias colaborativas relacionadas à indústria envolvem o desenvolvimento conjunto de novos jogos e redes de fornecedores qualificados, coordenados por uma empresa líder.

As empresas E2, E5 e E7 reportam utilizar a estratégia de desenvolvimento conjunto de jogos por necessitarem explorar novos mercados cujos investimentos seriam inviáveis para cada empresa isoladamente, compartilhando riscos e garantindo o fluxo de atividades necessárias ao projeto, minimizando incertezas e custos de transação (WILLIAMSON, 1975). Como destaca o empresário de E5, "[...] Era uma oportunidade para entrarmos no mercado de jogos. Tínhamos uma equipe forte na área de programação e a parte do nosso parceiro seria desenvolvimento de arte. Nós aí teríamos um produto que não conseguiríamos fazer sozinhos" (E5, 2007).

Com relação aos resultados da cooperação, o representante da empresa E2 percebeu ganhos de escala, desenvolvimento conjunto de produtos e ganhos de aprendizagem e melhoria de processo. Como menciona o mesmo respondente, "[...] Conseguimos um produto bastante sólido, que cada parceiro isoladamente não conseguiria fazer" (E2, 2007).

Já o representante da empresa E5 percebeu ganhos de aprendizagem, conforme argumenta, “[...] Iniciamos parte de nossa área de jogos através dessa parceria. Nossos profissionais se capacitaram devido a esse projeto. Trabalhando com uma boa empresa aprendemos a montar nossa equipe de arte" (E5, 2007).
Por fim, para a empresa E7, o projeto de desenvolvimento conjunto com seu parceiro ainda continua ocorrendo e aponta ganhos como performance, flexibilidade organizacional e ganhos de coespecialidades, afirmando que, "[...] Basicamente a gente está conseguindo viabilizar oportunidades que não conseguiria normalmente, pulando etapas do nosso desenvolvimento de forma saudável. Através da cooperação consigo responder hoje demandas que, sem a parceria, não poderia atender" (E7, 2007).

Essas evidências, ilustrando ganhos de aprendizagem e de coespecialidade, coerentes com as orientações de Ebers e Jarillo (1998).

Já a estratégia cooperativa de rede de fornecedoresqualificadosénormalmentecoordenada por uma empresa líder. Nesse tipo de estratégia, já aprofundada nos estudos de Dyer e Nobeoka (2000) sobre a Toyota, a empresa coordenadora, ao contrário de uma simples relação de compra junto ao fornecedor, engaja-se cooperativamente com os parceiros para constantemente aprimorar seus produtos. Conforme menciona o empresário de E3, "[...] Os fornecedores recebem internamente vários procedimentos". "[...] Todas as instruções de produção de arte têm um protocolo, um trabalho bem minucioso. $O$ trabalho em geral é feito de forma remota, com contatos via e-mail, skype e, de vez em quando, o pessoal volta aqui para revisar os métodos" (E3, 2007).

Essa evidência é reforçada pelo empresário de E8, "[...] A gente tem um projeto conjunto com nosso parceiro, e ele tem um projeto lá no estúdio dele. Mas tem um gerente de projetos dele que está aqui dentro, na nossa empresa, trabalhando ao lado do nosso gerente. Assim ele tem oportunidade de aprender os processos por osmose. E aí, no próximo projeto que for igual, ele já sabe o padrão, já sabe como deve ser" (E8, 2007).

No que se refere aos resultados atingidos pelo projeto colaborativo entre as empresas E3 e E7, observam-se ganhos de escala, maior flexibilidade, performance, aprendizagem e melhorias de processos. Nota-se também o aprendizado mútuo, que leva a empresa E3 a suportar melhor o processo de desenvolvimento de novos produtos e a redução de incertezas, outra importante fonte de custos de transação, conforme aponta seu empresário, “[...] Internamente a equipe recebe muitos procedimentos e orientações". "[...] O interessante é que a gente foi obrigada a trabalhar os processos e especificar tudo, coisa que a gente não fazia internamente. Passamos a usar inclusive nos nossos projetos. Os orçamentos ficaram mais estáveis, pois uma pessoa trabalhando internamente pode dizer que vai levar uma semana e acaba levando duas" (E3, 2007). 
Já flexibilidade e escala são pontos reforçados pelo empresário de E7, “[...] O ganho está no fato de ter escala em demandas pontuais. É muito gratificante atender à demanda de um cliente que, em princípio e sem equipe interna suficiente, seria inviável (E7, 2007).

Os ganhos destacados na utilização de estratégias colaborativas foram aprofundados nos estudos de Dyer e Nobeoka (2000) sobre a Toyota, que trabalha cooperativamente com os parceiros para aprimorar constantemente seus produtos. Esses relacionamentos de longo prazo e com crescentes níveis de confiança reduzem o oportunismo, muito frequente no mercado e com forte influência nos custos de transação (WILLIAMSON, 1975). Observa-se que tal benefício também foi apontado pelas empresas que adotam estratégias colaborativas na produção de jogos eletrônicos.

\section{Considerações finais}

0 presente artigo buscou apresentar uma caracterização da indústria brasileira de jogos eletrônicos bem como identificar as diferentes formas de coordenação das atividades produtivas adotadas pelas empresas que produzem jogos nesse setor. Conforme indicadores de importância estratégica e competência interna, informados pelas empresas, a internalização parece ser a estratégia mais recorrente, e as evidências apresentadas apontam que a adoção dessa forma de coordenação busca atacar os custos de transação, em especial aqueles atrelados a ativos de conhecimento e experiência, referentes à qualificação requerida para a produção dos jogos. Tais evidências estão alinhadas com as contribuições de Williamson (1975) e Geyskens, Steenkamp e Kumar (2006), que justificam a necessidade de altos investimentos em ativos específicos como importante fator de impacto nos custos transacionais. Tal realidade, segundo os dados levantados, parece associada à própria incipiência da indústria brasileira de jogos eletrônicos, ainda carente em termos de profissionais qualificados para a produção deles.

Apesar da predominância da produção interna, conforme teorizações dos autores e evidências da pesquisa, pode-se verificar o potencial da emergente forma de coordenação das atividades produtivas, através da cooperação, que vem sendo adotada por algumas empresas. Embora ainda pouco explorado, tal fato indica um caminho alternativo, entre as formas clássicas de produzir ou contratar, conforme orienta a Matriz CPC (CHILD; FAULKNER; TALLMAN, 2005).
As evidências demonstraram que essas estratégias colaborativas trouxeram ganhos de flexibilidade, desenvolvimento de novos produtos, coespecialização, maior escala, aprendizado, melhoria de processos e redução de incertezas, como já apontado por outros estudos em setores diversos (EBERS; JARILLO, 1998). Por outro lado, visam também mitigar os custos de transação, especialmente relacionados à redução do oportunismo e aos investimentos em ativos específicos. Tais resultados complementam outros estudos que evidenciam o potencial competitivo das estratégias colaborativas no contexto internacional, como por exemplo Jacobides e Billinger (2006) e Geyskens, Steenkamp e Kumar (2006), e de estudos brasileiros, como Balestrin e Verschoore (2008).

Ademais, este artigo procurou atender à escassez de estudos empíricos sobre a indústria de jogos, fato recorrente na literatura científica mundial de estudos organizacionais, em especial com relação ao contexto brasileiro. Nesse aspecto, os dados apresentados ilustraram um contraponto entre duas realidades estratégicas nas empresas de jogos: o predomínio de estratégias competitivas individualistas - o cavaleiro solitário (ASTLEY, 1984) e, por outro lado, a emergência do uso de estratégias colaborativas (JARILLO, 1993). Para o campo empresarial, espera-se que tais resultados provoquem reflexões sobre novas práticas gerenciais nas indústrias criativas, em especial aquelas que considerem o potencial da colaboração interorganizacional como fonte de vantagens competitivas, a exemplo do que foi evidenciado, de forma emergente, no caso da indústria de jogos eletrônicos.

Para finalizar, percebe-se a necessidade de investigações mais amplas que permitam melhor entender as diferentes condicionantes das estratégias de coordenação das atividades produtivas na indústria de jogos. Nesse sentido, salienta-se que as teorizações apresentadas são preliminares e visam, sobretudo, estimular novas investigações científicas no campo de estratégia sob a perspectiva emergente da colaboração, das relações interorganizacionais e dos custos de transação. Ressalta-se, também, que as evidências aqui apresentadas são resultado de um projeto mais amplo que está sendo desenvolvido pelos autores, buscando aprofundar o entendimento do contexto brasileiro e internacional da indústria de jogos eletrônicos. Aos interessados no tema, outros assuntos, como, por exemplo, propriedade intelectual, capital de risco, pirataria e governança, que são de elevada importância na dinâmica competitiva dessa indústria, ainda necessitam de maior aprofundamento e compreensão. 


\section{Referências}

ASSOCIAÇÃO BRASILEIRA DAS DESENVOLVEDORAS DE GAMES - ABRAGAMES. Plano diretor da promoção da indústria de desenvolvimento de jogos eletrônicos no Brasil 2004. Disponível em: <http://www.abragames.com. br>. Acesso em: 10 jul. 2006.

ASSOCIAÇÃO BRASILEIRA DAS DESENVOLVEDORAS DE GAMES - ABRAGAMES. A indústria brasileira de jogos eletrônicos. Disponível em: <http://www.abragames.com. br>. Acesso em: 10 dez. 2008.

ASTLEY, W. G. Toward an appreciation of collective strategy. The Academy of Management Review, v. 9, n. 3, p. 526-535, 1984.

BALESTRIN, A.; VERSCHOORE, J. R. Redes de cooperação empresarial: estratégias de gestão na nova economia. Porto Alegre: Bookman, 2008. 216 p.

BARROWCLOUGH, D; KOZUL-WRIGHT, Z. (Orgs.). Creative industries and developing countries: voice, choice and economic growth. New York: Routledge, 2008. 334 p.

BRASIL. Ministério da Ciência e Tecnologia. Programa para Promoção da Excelência do Software Brasileiro. Sociedade Brasileira para Promoção da Exportaçao de Software SOFTEX. Tecnologias de visualização na Indústria de jogos digitais: potencial econômico e tecnológico para a indústria brasileira de software. 2005. Disponível em: <http:// observatorio.softex.br>. Acesso em: 10 jul. 2006.

CHILD, J.; FAULKNER, D.; TALLMAN, S. Cooperative strategy: managing alliances, networks and joint ventures. 2. ed. Oxford: Oxford Press, 2005. 472 p.

COASE, R. H. The nature of the firm. Economica, v. 4, n. 16, p. 386-405, 1937.

COMMONS, J. R. Legal foundations of capitalism. Macmillan: New York, 1924.

COMMONS, J. R. Institutional economics. American Economic Review, v. 21, n. 4, p. 648-657, 1931.

DFC INTELLIGENCE. DFC Intelligence forecasts video game market to reach $\$ 47$ billion by 2009. 2007 Disponivel em: < http://www.dfcint.com/wp/?p=189>. Acesso em: 10 jan. 2008.
DYER, J.; NOBEOKA, K. Creating and managing a high-performance knowledge-charing network: the Toyota case. Strategic Management Journal, v. 21, n. 3, p. 345-367, 2000.

EBERS, M; JARILLO, C. The construction, forms, and consequences of industry networks. International Studies of Management \& Organization, v. 27, n. 4, p. 3-21, 1998.

GEYSKENS, 1; STEENKAMP, J. E. M.; KUMAR, N. A meta-analysis of satisfaction...research using key informants. Academy of Management Journal, v. 49, n. 3, p. 519-543, 2006.

GRANTHAM, A.; KAPLINSKY, R. Getting the measure of the electronic games industry: developers and the management of innovation. International Journal of Innovation Management, v. 9, n. 2, p. 183-213, 2005.

HAIR, J. F. et al. Fundamentos de métodos de pesquisa em administração. Tradução de Lene Belon Ribeiro. Porto Alegre: Bookman, 2005. 472 p.

JACOBIDES, M. G.; BILLINGER, S. Designing the boundaries of the firm: from "make, buy, or ally" to the dynamic benefits of vertical architecture. Organization Science, v. 17, n. 2, p. 249-261, 2006

JARILLO, C. On strategic networks. Strategic Management Journal, v. 9, n. 1, p. 31-41, 1988.

JARILLO, C. Strategic networks: creating the borderless organization. Oxford: Butterworth-Heinemann, 1993. $178 \mathrm{p}$.

JOHNS, J. Video Games Production Networks: value capture, power relations and embeddedness. Journal of Economic Geography, v. 6, n. 2, p. 151-180, 2006.

NALEBUFF, B. J.; BRANDENBURGER, A. M. Co-opetição. Rio de Janeiro: Rocco, 1989. 312 p.

TSCHANG, F. T. Videogames as interactive experimental products and their manner of development. International Journal of Innovation Management, v. 9, n. 1, p. 103-131, 2005.

WILLIAMS, D. Structure and competition in the U.S. Home Video Game Industry. The International Journal on Media Management, v. 4, n. 1, p. 41-54, 2002.

WILLIAMSON, 0. E. Markets and hierarchies: analysis and antitrust implications. New York: Free Press, 1975. 286 p.

\title{
Coordination of production activities in the Brazilian electronic games industry: hierarchy, market or alliance?
}

\begin{abstract}
This study aims to understand how games firms coordinate their production activities in the Brazilian Electronic Games Industry. To do so this paper makes use of the theories of transaction costs as well as of inter-organizational relationships to analyze firms' strategic choices with regard to games production: made in-house (Hierarchy), bought on the market (Market), or collaboration with a partner (Alliance). The research was conducted with firms belonging to the Brazilian Game Developers Association and data were collected from electronic surveys and interviews. The results show that firms tend to internalize activities of game production, in particular because of transaction costs associated with asset specificity (knowledge specialization and scarce availability of skilled labor). However, market relations were found relating to activities considered, by the firms, to be of less strategic importance as well as collaborative projects which provided firms with results such as reduction of uncertainty, greater flexibility, process improvement and mutual learning.
\end{abstract}

Keywords

Creative industries. Inter-organizational relationships. Video games. Transaction costs. 